\title{
Participating regions
}

Buskerud County, Norway

Darling Downs and South West Queensland, Australia

Devon and Cornwall, England

Essex, England

Flanders, Belgium

Gaborone, Botswana

Glasgow, Scotland

Helsinki, Finland

Jämtland, Sweden

Kent, England

Lesotho (as a small whole-country region)

Melbourne, Australia

Northern Illinois, United States of America

Puglia, Italy

South Transdanubia, Hungary

Thames Gateway (south-east London), England

Värmland, Sweden 
Chris Duke, Michael Osborne, and Bruce Wilson - 9781526110497 Downloaded from manchesterhive.com at 04/26/2023 03:31:01PM via free access 